hepatic abscess in India, we should expect to meet with a greater frequency of these abscesses between the middle of December and the beginning of March; but such is not the case. Even among the eighteen cases here recorded two only pertain to the cold season; all the others occurred between the months of June and November, a period characterised in Bombay by an equably high temperature and by the great prevalence of malarial fevers.

Cannes.

\section{CATARACT EXTRACTION PERFORMED ON AN INSANE PATIENT.}

\section{Bx T. H. B I C K E R T O N, M.R.C.S.}

THE following case of cataract extraction may be of some little interest from the fact that it occurred in the person of an insane individual. The patient in question is an inmate of the Rainhill County Asylum, and 1 have to thank Dr. Rogers, medical superintendent of that institution, for his permission to perform the operation, and also for his permission to mention the case. The history is as follows:-

John T- - aged seventy-one, was first admitted into the asylum in 1868 as a suicidal patient. Between 1868 and 1872 he was twice discharged, and being in the latter year readmitted for the third time, he has remained an inmate ever since. The first note that there is about his vision is in the asylum book for 1876 , where the remark is made that he is "gradually losing sight from cataract." His own statement, however, on the matter was that the sight of the right eye had been lost for twenty years. The vision of the left eye gradually failed, and more than twelve months ago he became totally blind, and since then he had to be led about by another patient. The right cataract was of a China-white variety, and as the pupil acted well, and the vision was fair for light and shade, it was considered that there was every probability of a successful result being arrived at. The patient was anxious to be operated on. The eye (right) being made insensitive by two applications of ten drops each, of an 8 per cent. solution of cocaine, the incision was carried as nearly approaching a Graefe's as possible, the wound being entirely in the sclerotic. On making the iridectomy, the lens was seen to be bulging greatly towards the wound; and on dividing the capsule, a sudden gush of fluid showed the cataract to be a fluid one, and carried up with the rush to behind the posterior lip of the wound was a small, hard-looking, red nucleus. Lying now in the pupillary space was the white capsule, and this after one or two attempts was removed entire by means of a pair of iris forceps, its slight adhesion to the posterior surface of the nucleus giving way to gentle side-to-side movements. To depress the nucleus so as to bring its upper margin in front of instead of behind the posterior edge of the wound, where the rush of fluid had carried it, was a matter of difficulty, but this was at last overcome by introducing a sharp needle into the nucleus and pushing it down. Slight pressure being exerted behind the wound at the same time, the upper margin of the nucleus disengaged itself, and presenting through the wound, quickly came out, and the operation was completed. Every means were now taken to keep the patient quiet; he was allotted a special attendant, and as much as possible the importance of absolute rest was impressed upon him. Owing to the capsule being entirely removed - a most unexpected, rare, and fortunate occurrence in this variety of cataract operation-all fear of inflammation of the iris could be dismissed, and one's anxiety was devoted to promoting a rapid union of the wound. All went well for five days, but on the sixth night, during the temporary absence of the attendant, and in spite of all warnings, he strained greatly to relieve his bowels, with the consequence that the wound, when seen the following morning, was opened up and a bead of vitreous was presenting. Firm pressure was then applied, and bark, port wine, eggs, and stout were given to keep up his strength and to promote union. Matters again did well until the twelfth day, when in consequence of his sitting up in bed to get his tea on the previous evening, the outer third of the wound was seen to have again given way. The powers of union being thus so poor, increased stimulation by port wine, stout, bark, and food was given, and every care taken to prevent any further untoward movements on his part, with the result that on the seventeenth day the wound was again united in its whole length, and from this time onward things went well, but it was not until a month had elapsed from the operation that it was deemed safe to allow him to get up. The final result of the operation is a gratifying one. On testing his vision, four months after the operation, for distance, with $\mathrm{a}+10 \mathrm{D}$ lens, it was perfect, he being able to read at a distance of 20 feet every letter of Snellen 20; and his near vision was also perfect, he being with $\mathrm{a}+14 \mathrm{D}$ lens able to read Jaeger 1 with fair fluency. In fact, with that eye his vision was normal.

In addition to the operation being performed on a lunatic, there are other points of interest in the case-viz., the fluidity of a cataract occurring in a man aged seventy-one, the entire removal of the capsule, and the difficulty that was experienced in attaining firm union. It was the knowledge of the general impairment of nutrition common to the insane, and almost certain to be met with in any man of seventy-one, that induced me to make the incision entirely in the vascular sclerotic, and as far away as was consistent with safety from the non-vascular cornea, and the after-results showed, I think, that this was a wise precaution. Also, $1 \mathrm{am}$ inclined to believe that the fluidity of the lens lends truth to the old man's statement that the cataract had existed for twenty years, and the dense condition of the capsule, and the ease with which it came away from its usual attachments, corroborate this. This point may be cleared up when the left cataract is extracted and its consistency known.

Liverpool.

\section{NOTES ON HIP-JOINT ABSCESS. ${ }^{1}$}

\section{BY EDMUND OWEN, F.R.C.S.,}

SURGEON TO THE HOSPITAL FOR SICK CHILDREN, GREAT ORMOND-STREET

THere were in the Louise ward of the Children's Hospital at the time that these remarks were put together five cases of hip-joint abscess, all of which had been subjected to the same ultimate treatment.

The occurrence of abscess in the progress of disease of the hip-joint is common enough, but the question as to what had better be done with such abscess cannot always be answered off-hand. The signs of the formation of abscess may be increasing pain, a rise of a few degrees in the temperature chart, a fulness in the upper part of the wasted thigh, and a decline in the general health of the child. But sometimes pus collects without the surgeon's attention being specially attracted to the part, and the abscess is discovered, almost by chance, as an obscurely fluctuating fulness below or in front of the great trochanter, at the origin of the adductors, or just beneath the middle of Poupart's ligament. In the first and second case the pus had probably escaped through the thin posterior part of the capsular ligament, and thence worked its way round. In the last case, a comparatively rare one, it had made its exit through the perforation in the front of the capsule by which the bursa beneath the psoas communicates with the interior of the joint.

Aspiration.-I confess that my experience with aspiration of hip abscess has not been specially satisfactory. Although the instrument used may have been a slender one, still within a few days of its employment pus has been seen leaking from the site of the puncture. In two of the five cases under consideration a disappointing leakage had thus occurred. Nevertheless, repeated aspiration should always start the treatment of hip abscess, unless the inflammatory condition be acute and the pressure symptoms severe. If the pus be thick and curdy the cannula will not serve, and other means must be employed ; so also if the re-accumulation of pus be rapid and repeated puncture fail to make headway. Lastly, if aspiration be followed, as it may be, by acute local inflammation and constitutional disturbance, something more is needed.

Incision.-From one or other of the reasons just enumerated the hip-joint abscess in all five children (their ages varied from three to seven years) had to be freely incised by the house-surgeon, Mr. Lewis. From some of the abscess cavities, after the escape of pus, much curdy matter, granular débris, and shreddy material were squeezed or 